\title{
Intramedullary nail: the past, present and the future - a review exploring where the future may lead us
}

Noah Wong Wei Kang' ${ }^{1}$, Wen Po Jonathan Tan', Yue Min Crystal Phua', Amelia Tan Gek Min', Kishan Naidu', Kandiah Umapathysivam 1 , Peter Jonathan Smitham ${ }^{2}$

${ }^{1}$ Adelaide Medical School, ${ }^{2}$ Adelaide Medical School; Department of Orthopedics and Trauma, Royal Adelaide Hospital \& Discipline of Orthopedics \& Trauma, The University of Adelaide

Keywords: orthopedic, carbon fiber nails, expandable nails, coated nails, intramedullary nails

https://doi.org/10.52965/001c.25546

\section{Orthopedic Reviews}

Vol. 13, Issue 1, 2021

\section{Background}

Intramedullary nails (IMNs) are the current gold standard treatment for long bone diaphyseal and selected metaphyseal fractures. The design of IMNs has undergone many revisions since its invention in the $16^{\text {th }}$ century, with a dramatic increase in novel designs in recent years aiming to further improve intramedullary fixation techniques.

\begin{abstract}
Aims
To map the evolution of IMNs in orthopedic surgery, discuss the limitations and complications of current IMNs and identify novel IMNs that may influence future design innovations.
\end{abstract}

\section{Methods}

We undertook a scoping review on the status of orthopedic IMNs by reviewing Google Scholar with the following keywords. Publications and patents selected for retrieval were initially assessed on the title and abstract by five independent reviewers. 52 papers were retrieved for complete text examination, and secondary references were checked from these papers. The results were discussed within the research group and consensus was obtained describing novel IMNs.

\section{Results}

Novel IMN designs include growth factor and/or antimicrobial coatings targeting fracture healing and perioperative infection risk, respectively; minimally invasive expandable IMNs to avoid the need for interlocking screws; and novel materials such as carbon fiber for their theoretically superior biomechanical properties and avoidance of artifact on CT and MRI imaging.

\section{Conclusion}

The novel IMNs proposed in recent years collectively aim to improve intramedullary fixation techniques by reducing operative time and radiation exposure, improving fracture healing or monitoring bone cancer progression. However, more research and development are necessary to solve these complex problems.

\section{INTRODUCTION}

THE BEGINNINGS OF INTRAMEDULLARY NAILS (IMNS)

Orthopedic implants are constantly being refined with the introduction of new technologies and evolving clinical requirements. However, as demonstrated in the past, novel designs can inadvertently ignore past failures and as Dr. Carl Sagan (1980) said, "You have to know the past to un-

\footnotetext{
a Corresponding author:

Noah Wong Wei Kang

217 Waymouth Street, Adelaide, SA 5000

+61422026847

noahwkwong@gmail.com
} 
derstand the present.” This statement is particularly true when aiming to see the future directions of the design of IMNs.

The first intramedullary device as described in the 16th century by Bernardino Da Sahagun. He documented Aztec physicians using solid, wooden pegs for the treatment of non-unions. ${ }^{1}$

In 1875 , Heine introduced the use of ivory IMNs for femoral shaft fractures in Germany ${ }^{2}$ and the use of ivory later became the material of choice for IMNs until $1910 .^{3}$ The period between 1875 to 1910 also witnessed the development of interlocking nails and pins made from ivory to improve rotational stability. ${ }^{4}$ It later became apparent that ivory materials are resorbable. This meant that ivory implants could not provide sufficient stability for fracture healing, particularly in cases involving delayed unions. ${ }^{5}$

This eventually led to experiments with various other metallic nails over the years. In 1911, Lilienthal used aluminum intramedullary splints for the treatment of femoral shaft fractures; in 1913, Georg Schöne used silver pins for the treatment of upper limb fractures ${ }^{6,7}$; and in 1921, Oskar Müller-Meenarch implanted internal splints called "Bolzen" that were made from stainless steel or chromicized brass. 8

The widespread transition from ivory to metal happened during World War I, where Groves reported the use of metallic implants for the treatment of gunshot wounds. ${ }^{9}$ Unfortunately, due to high infection rates and reported cases of fretting, Groves' technique was initially not universally accepted, and progress stalled. ${ }^{10,11}$

In 1931, Smith Peterson's report on the successful application of stainless-steel nails for femoral neck fractures and his introduction of metal, solid triflanged nails for subcapital femoral neck fractures revolutionized fracture fixation. It became the standard management for the next 40 years. ${ }^{11,12}$ However, there were limitations to Smith Peterson's IMN, including documented cases of femoral fractures among inexperienced surgeons and a higher risk of postoperative complications such as iatrogenic lateral femoral cutaneous nerve injury. Hence, further improvements in design were demanded by clinicians. ${ }^{6,8}$

As shown in figure 1, early IMNs can be characterized as solid and inflexible nails. These nails quickly became obsolete due to high failure rates associated with a discrepancy in nail-bone stiffness. However, it was an important invention that subsequent designs leveraged to extend the indications and improve clinical outcomes of fracture fixation.

\section{PRESENT: CURRENT IMN IN PRACTICE}

Gerhard Küntscher is often credited as one of the founding fathers of the modern day intramedullary nail. ${ }^{13}$ His first invention was the V-shaped, stainless steel IMN for femoral shaft fractures, followed by the cloverleaf-shaped IMN in the late 1940 s. ${ }^{14}$ The latter was particularly well-received for its low complication rates and ease of implantation. ${ }^{15}$

Both Küntscher's V-shaped and cloverleaf-shaped IMNs nails were designed with a slotted configuration. The slot allowed for elastic radial compression of the IMN to maximize bone-nail contact for rotational and axial stability. ${ }^{16}$ The slot also allows the nail to adapt to the unique infra- structure of the medullary canal, thus avoiding undesirable mechanical stress during implantation. ${ }^{16}$

In the 1960s, Huckstep introduced titanium metal for IMNs after the invention of image intensifiers. The titanium IMNs boasts superior mechanical properties such as a Young Modulus closer to the intact diaphyseal cortical bone, higher fatigue, and yield tensile strength and lower density as compared to its predecessor, the medical-grade stainless steel IMNs. ${ }^{13}$

The turning point from slotted to non-slotted configuration occurred in 1986 when Russel \& Taylor introduced the non-slotted femoral IMN that was made possible using a gun-drilling computerized machining technique. ${ }^{16}$ This technique allowed for the construction of an IMN with lower bending stiffness and better rotational stability. The non-slotted IMNs subsequently became the preferred device up to the $21^{\text {st }}$ century.

Over the years, numerous surgical techniques were introduced to enhance the implantation of IMNs. Intramedullary reamers were introduced in 1942 to allow for the insertion of larger IMNs to promote bone-nail contact for improved implant stability. In 1953, interlocking screws were introduced after nearly 60 years since they were first considered in the ivory interlocking pin design. ${ }^{17}$ Between 1975 to 1985, guide rods, capitalizing on the benefit of a cannulated IMN design, were introduced to direct the implantation of IMNs. ${ }^{15}$

\section{METHODS}

We undertook a scoping review on the status of orthopedic IMNs by reviewing Google Scholar with the following keywords (orthopedic, intramedullary nails, coated nails, expandable nails, carbon fiber nails). Publications and patents selected for retrieval were initially assessed on the title and abstract by five independent reviewers. 52 papers were retrieved for complete text examination, and secondary references were checked from these papers. The results are discussed below.

\section{RESULTS}

\section{FUTURE: NOVEL IMNS}

Three main groups of novel IMNs were identified in the last twenty years. They are divided into expandable, coated, and carbon fiber nails.

\section{EXPANDABLE INTRAMEDULLARY NAILS}

Expandable IMNs were first introduced in 1999 and became widely known as the Fixion IMN (CarboFix Orthopedics NC, USA). ${ }^{18}$ The Fixion IMN (figure 2) was indicated to treat acute diaphyseal fractures, pathological fractures, nonunions, and malunions of long bones. ${ }^{18}$ It was also suitable for osteoporotic bones, osteotomy, and other revisional procedures that had failed in its initial fixation methods. ${ }^{18}$

The Fixion IMN is hydraulically expanded with pressurized saline throughout the length of the nail, thereby increasing the diameter by up to $160 \%$ of its original size. ${ }^{18}$ Expandable nails aimed to avoid the need for reaming and 


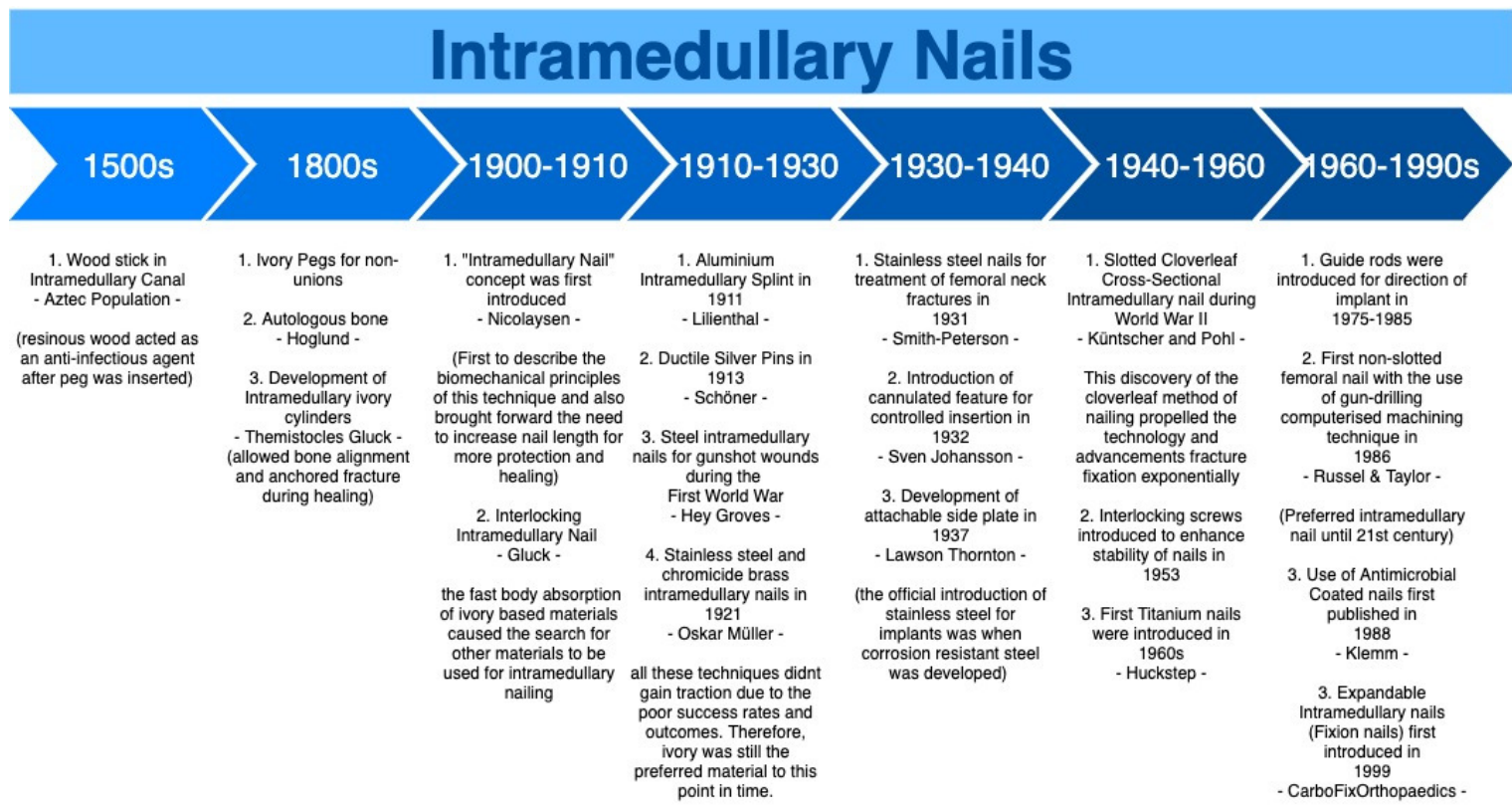

Figure 1. Timeline of the evolution of IMNs

the use of interlocking screws by providing rotational stability with the four longitudinal reinforcement bars. ${ }^{18,20}$

By negating the need for distal interlocking screws, expandable IMNs potentially reduce the operation time and radiation exposure to both the patient and the surgeon. Papers have reported that the average time for insertion of expandable intramedullary nails can be as short as 35 minutes ${ }^{18,21}$ Additionally, with only a single incision point required to implant expandable nails without the need for locking screw insertion, the procedure is minimally invasive. $^{22}$

Another potential advantage of expandable IMN is its narrow diameter in its unexpanded form. This negates the need to ream the medullary canal before implantation, thus avoiding damage to the surrounding bone and vascular structures. ${ }^{20}$

The further potential advantage of these nails is their ability to conform to the unique geometry of the medullary canal, allowing for a larger bone-nail contact which theoretically implies greater stability, bending stiffness, and more even pressure distribution. ${ }^{18,20,22}$

However, expandable nails have reported some contraindications and complications that must be considered when considering them as a novel nail design. Contraindications for the Fixion IMN included fractures with greater than $50 \%$ fragmentation, conditions with brittle bones such as osteogenesis imperfecta, and fractures involving the head or neck of the femur and humerus due to the risk of iatrogenic new or extension of fracture. ${ }^{18,23}$

Unfortunately, papers have reported an overall complication rate of up to $13 \%$ for the Fixion expandable IMN. ${ }^{24}$ Identified intra-operative complications include device-induced fracture extension, inflator breakage, pre-inflation leakage of saline, and bending of the Fixion IMN upon in-

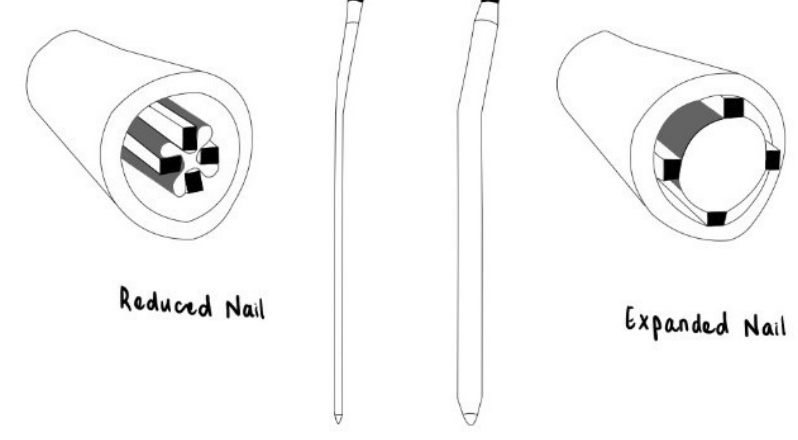

Figure 2. Illustration of Fixion IMN - a cross-section of a long bone pre-and post-expansion ${ }^{19}$

sertion leading to device failure. ${ }^{24}$ The major postoperative complication identified with the Fixion IMN involves the limb's shortening by up to $1 \mathrm{~cm} .{ }^{24}$ A consideration for the Fixion IMN is the need for an additional procedure to remove the IMN before cremation to prevent an explosion of the nail. ${ }^{25}$

The above considerations subsequently led to the demise of the Fixion IMN in routine practice.

Other designs of expandable IMNs proposed over the years to capitalize on the potential advantages of a selflocking IMN - minimally invasive, shorter procedure time, avoidance of reaming, and avoidance of interlocking screws. Unfortunately, there has been limited published literature regarding these newer designs.

In 2006, the United States patented a novel expandable IMN (igure 3) that used splines to stabilize long bone fractures. ${ }^{19}$ 
In 2019, a 'Screwless Blade Expandable Nail' (figure 4) was introduced by Tianjin Walkman China. ${ }^{26}$

In 2020, a new expandable IMN - known as EXPN (igure 5) was tested in an animal study in Germany. ${ }^{27}$ This IMN featured expandable segments and bridging elements but proved to be weaker in neutralizing axial compressive forces when compared to traditional solid IMNs. ${ }^{27}$

However, common to all expandable IMN designs, the challenge faced is removing the nail when complications do arise. However, no studies have been conducted or reported on the ease of removing these novel expandable IMNs if required at a later stage.

Although several novel IMN designs have been explored in recent years, few or no clinical studies have been published to demonstrate the hypothesized benefits, and more evidence would be demanded before expandable IMNs can be accepted into standard practice.

\section{COATED INTRAMEDULLARY NAILS}

Coated nails can be categorized into coatings to prevent infection or coatings to promote fracture healing. Infection prevention has been attempted with either antibiotic coating (custom or manufactured) or antiseptic coatings.

\section{ANTIBIOTIC COATINGS AND DELIVERY SYSTEMS}

Peri-prosthetic intramedullary nail infections reportedly cost $80 \%$ more than non-infected cases and require a length of stay over double that of a non-infected case. ${ }^{28}$

Organisms associated with peri-prosthetic infections classically adhere to the implant surface, forming a protective biofilm against antimicrobials. ${ }^{29}$ Therefore, peri-implant infections are often difficult to treat, requiring treatment with revision operations and long-term systemic antibiotics. ${ }^{30}$

The disadvantages of systemic antibiotics delivery include insufficient drug concentration at the fracture site and potential systemic toxicities. ${ }^{31}$ These trends demonstrate a substantial benefit in incorporating antimicrobial surface coating technology with IMNs. Hence, the increased interest and development in new nailing systems can potentially reduce infection rates.

The bio-resorbable Poly-D,L lactic acid (PDLLA) matrix has been proposed as a local delivery medium for both antibiotic and growth factors in implants. It has been increasingly popular in many dental and orthopedic devices due to its ease of handling, good soft tissue response, and ability to resorb over time.

PDLLA was first used in the UTN PROtect nail (Synthes, Massachusetts, USA)) - an antibiotic-coated interlocking nail in 2006. ${ }^{32}$

Further revisions led to the modern day Synthes Expert Tibial Nail PROtect (ETN PROtect ${ }^{\mathrm{TM}}$ ). Currently, the only manufactured gentamicin sulfate coated tibial nail in the market with a PDLLA delivery medium. ${ }^{16,33}$ Gentamicin sulphate is delivered to the surrounding tissue in a burst release profile immediately after implantation - over $40 \%$ of the antibiotic is released within an hour, $70 \%$ within 24 hours, and $80 \%$ within 48 hours of implantation. ${ }^{30}$ This system allows for the delivery of a local concentration 1000

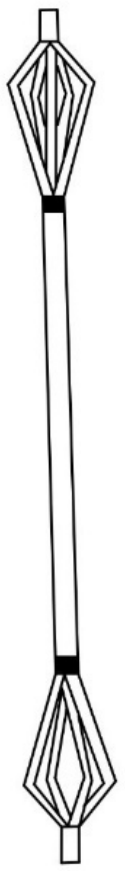

Figure 3. Illustration of US Patent Expandable Orthopeedic Device ${ }^{19}$

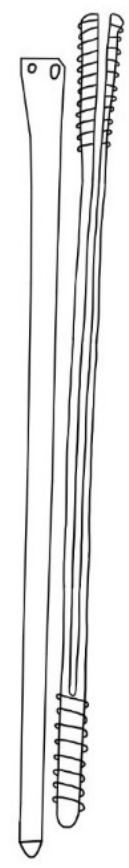

Figure 4. Illustration of Screwless Blade Expandable Nail ${ }^{26}$

times greater than systemic antibiotics. ${ }^{34}$ The cost of the ETN may vary. However, one paper reported that in Belgium and ETN without the coating would cost 508.95 euro compared to 684.00 euro when coated (ETN PROtect $\left.{ }^{\mathrm{TM}}\right) .{ }^{35}$ However, no large economic cost-benefit study or randomized 
controlled study has been conducted to rationalize the widespread adoption of the ETN Protect ${ }^{\mathrm{TM}}$ nail to prevent infections.

Other coatings being considered to include the PolymerLipid Encapsulation Matrix (PLEX) (PolyPid Ltd., Israel) a biodegradable delivery system made of alternating layers of polymers and lipids that enables controlled and continuous drug delivery over periods ranging from days to several months. ${ }^{35,36}$ With PLEX, drugs can be delivered by themselves or inserted during surgery as an injectable material or coating for medical devices.

The safety and efficacy of PLEX have been trialed with the controlled release of doxycycline (doxycycline/polymerlipid encapsulation matrix [D-PLEX]) most recently in an abdominal surgery incision model of miniature swine. ${ }^{37}$ The D-PLEX matrix did not show any evidence of systemic toxicities and was essentially absorbed at 6 months, demonstrating its safety and favorable degradability profile ${ }^{37}$ However, further research is warranted to evaluate the safety and degradability profile in humans.

\section{CUSTOM-MADE ANTIBIOTIC COATING CEMENTS}

Custom-made antibiotic-coated cement for IMNs was first published 30 years ago by Klemm et al. and has been improved upon several iterations. ${ }^{38}$ The antibiotic-coated cement is typically used to treat an established infection rather than for infection prevention. By doing so, a directed antibiotic regime based on established bacterial susceptibility can be conducted, preventing the development of antibiotic resistance. ${ }^{32}$ Studies have reported that custom-made antibiotic cement nails could clear known infections by 6 months in $76 \%$ of cases. ${ }^{39}$

However, limitations and challenges of this approach include: requiring an antibiotic that is heat resistant to the cementing process; arduous and long preparation time for the fabrication of the antibiotic cement nails ${ }^{40}$; risk of adherence of cement to the plastic sleeve used to create the implant $^{40}$; and the increased diameter of the medullary canal required to accommodate the cement consequently requiring the need for additional reaming or the use of a thinner nail thereby compromising the strength of fixation. ${ }^{41}$

\section{ANTISEPTIC COATING}

Silver-coated IMNs have been explored as an alternative to antibiotic coatings due to their lower risk of developing antibiotic resistance. Silver in its cation state $\left(\mathrm{Ag}^{+}\right)$induces cell death by reacting and disrupting cell membranes, metabolic proteins, and bacteria ${ }^{42}$ This multilevel microbial mode of action, compared to the focal action of antibiotics, prevents the development of resistance. ${ }^{43}$

Silver is also hypothesized to have a broad bactericidal spectrum. ${ }^{36}$ A study by Hardes et al. showed an infection rate of $5.9 \%$ in patients with silver-coated endoprosthesis versus an infection rate of $17.6 \%$ in patients with uncoated prostheses. ${ }^{44}$

Although there have been concerns regarding local and systemic toxicities associated with higher doses of silver, they are rarely seen in clinical practice. ${ }^{45}$ Although copper

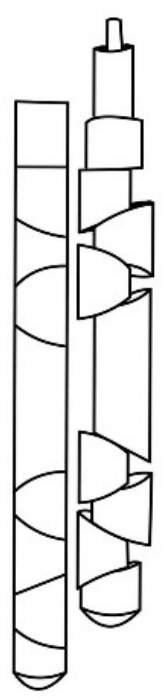

\section{Figure 5. Illustration of the Novel Expandable Nail Model $^{27}$}

and zinc are known to exhibit broad-spectrum antimicrobial properties, they are not as widely utilized as silver due to their systemic toxicities. ${ }^{46}$

Iodine-oxide antiseptic coating is another alternative to prevent periprosthetic infections. ${ }^{47}$ This technique has been implemented on titanium plates and endoprostheses but has yet to be trialed IMNs. ${ }^{47}$

A recent meta-analysis combining 1307 patients with coated implants demonstrated that antimicrobial coatings effectively prevent periprosthetic infections. ${ }^{48}$

\section{GROWTH FACTOR COATINGS}

Multiple attempts to promote bone healing have been explored to address complications such as delayed fracture healing and non-unions associated with long bone diaphyseal fractures. ${ }^{49}$

Growth factors such as bone morphogenetic proteins (BMPs), insulin-like growth factor-1 (IGF-1), and transforming growth factor- $\beta 1$ (TGF- $\beta 1$ ) have demonstrated osteoinductive effects. ${ }^{50}$ Studies have shown that the local application of growth factors may improve the clinical outcome in fracture treatment - biomechanical studies showed significantly higher torsional stiffness and maximum load in the growth factor group; histological analyses showed a larger callus volume in the growth factor group. .0

However, the manipulation of growth factors to stimulate fracture healing is a complicated process. The physiology of growth factors involves an intricate cascade of intracellular and extracellular interactions. Inability to alter growth factors after implantation and the risk of dysregulated growth stimulation leading to oncological bone diseases are challenging to be resolved before growth-stimu- 
lating coatings can be popularized.

Along with the pursuit for the appropriate combination of growth factors for fracture healing, extensive research to identify a suitable medium to deliver the growth factors has been conducted. 51

Options for the delivery medium investigated include:

- Synthetic polymers, e.g., PDLLA

- Natural polymers, e.g., collagen or alginate

- Microparticles and nanoparticles

- Biomimetic coatings, e.g., ceramics

To date, the majority of the data on growth-factor coated nails have been based on animal models with limited randomized controlled trials for efficacy and effectiveness in humans.

\section{OVERVIEW OF COATED INTRAMEDULLARY NAILS}

Coated intramedullary nails (IMNs) have the potential to reduce the risk of infections and delayed unions. Although the different coatings have been discussed separately in the above sections, multifunctional combination coatings have been attempted to improve clinical outcomes - growth factor and antibiotic combination coatings.

More research is required to optimize the delivery of drugs or chemicals further, minimize the toxicity profile, improve cost-effectiveness and improve ease of application. ${ }^{52}$ Ultimately, IMN coatings must be capable of surviving the insertional process and provide local drug delivery in a perfectly timed fashion without compromising on the overall stability of fracture fixation or excessively increasing the operative time.

These challenges, along with the increased regulatory complexities for drug-eluding medical devices for therapeutic purposes, have hampered the development of coated implants. ${ }^{53}$

\section{CARBON FIBER INTRAMEDULLARY NAILS}

Biomechanical studies of metal IMNs have shown that most of the weight-bearing load is borne by the IMN due to the large bone-implant discrepancy in the Young's modulus of elasticity. ${ }^{16}$ In the absence of adequate load-bearing on the surrounding bone, peri-implant osteopenia is common with metal IMNs. ${ }^{54}$ Hence, various materials have been trialed to develop an IMN with a modulus of elasticity closely matched to the bone. ${ }^{16}$ One such material is carbon fiber.

Carbon fibers are created by multiple layers of fibers, 5-10 micrometers in diameter. Each fiber is formed by carbon atoms arranged in a regular hexagonal pattern. The ability to vary the arrangement of fibers can alter the tensile strength of the matrix, thereby providing the opportunity to manipulate the tensile strength at various focal points as intended.

CarboFix, a commercially available composite IMN, is made up of carbon fiber reinforced with a poly-ether-etherketone (PEEK) matrix. The carbon fibers bear the load, and the PEEK matrix holds the fibers in place. ${ }^{16}$ Variation of the composition of carbon fibers and polymer matrix allows customization of the desired stiffness and strength to match the biomechanical environment. ${ }^{55}$ This customiz- ability allows for a modulus of elasticity similar to bone, decreasing the "stress shielding" effect and promoting callus formation. ${ }^{56}$

Composite carbon fiber IMNs claim to have an improved fatigue life compared to conventional metallic IMNs. An implant's fatigue failure results from progressive structural damage that occurs when a material is subjected to cyclical loading. Commercially available CFR-PEEK nails claim to be able to withstand one million fatigue cycles without implant failure. ${ }^{57} \mathrm{~A}$ recent prospective study on CFR-PEEK IMNs has shown 95\% union rates in femoral fractures and the absence of hardware failure. ${ }^{58}$ However, this study is limited by a lack of a control group and a small sample size of 20 subjects.

Another potential advantage of carbon fiber IMNs has been increasingly attractive due to their radiolucency properties. The provision of artifact-free images allows for evaluating bone tumor progression or recurrence in bone tumors requiring prophylactic intramedullary nailing. ${ }^{55,56}$ Moreover, with lesser radio interference and a more comprehensive evaluation of pathology, an appropriate radiation dose can be administered to patients to reach the therapeutic threshold for adjuvant radiotherapy. ${ }^{59}$

Conversely, carbon fiber implant's radiolucency may pose a challenge in identifying and removing a broken implant. However, CFR-PEEK nails have displayed good stability and favorable mechanical properties for fracture healing - low risk of device failure. ${ }^{58}$

A recent comparative study between CFR-PEEK plates and stainless steel plates has shown encouraging shortterm results in treating distal femur fractures with comparable non-union, re-operation, and hardware rates to those treated with stainless steel plates. ${ }^{60}$ This encouraging evidence suggests the CFR-PEEK may be a viable alternative for IMNs.

Despite its laboratory-confirmed biomechanical and radiological benefits, there is currently insufficient literature regarding long-term outcomes and cost-effectiveness for carbon fiber nails to be widely utilized in the market. With its increasing availability and usage, ${ }^{55}$ further randomized controlled studies and cost-benefit studies are needed to confirm the performance of carbon fiber as an alternate material for intramedullary nails.

\section{DISCUSSIONS}

The limitations of current intramedullary nails (IMNs) can be divided into insertional limitations or postoperative complications, as summarized in Table 1.

Reviewing the literature highlighted several advantages and disadvantages with the novel IMN designs summarized in Table 2.

Despite many attempts to improve the design of IMNs, each new design still has limitations that need to be overcome, and further clinical trials are required to confirm the theoretical advantages described.

\section{CONCLUSION}

The design of intramedullary nails has undergone countless 
Table 1. Limitations in current intramedullary nails

\begin{tabular}{|c|c|}
\hline Insertional Limitations & Postoperative Complications \\
\hline $\begin{array}{c}\text { Location of entry point for a straight nail } \\
\text { Damage to adjacent structures upon insertion } \\
\text { Time required to lock the nail proximally \& distally } \\
\text { Radiation risk associated with an image intensifier guidance }\end{array}$ & $\begin{array}{c}\text { Infection risk } \\
\text { Non-union }\end{array}$ \\
Radio-interference of tumors
\end{tabular}

\section{Table 2. Advantages vs. Disadvantages of Novel IMNs}

\begin{tabular}{|c|c|c|}
\hline \multicolumn{3}{|c|}{ Novel Intramedullary Nails } \\
\hline & Advantages & Disadvantages \\
\hline $\begin{array}{l}\text { Expendable } \\
\text { Nail }\end{array}$ & $\begin{array}{l}\text { Superior Rotational Stability } \\
\text { Greater Flexural Stiffness } \\
\text { Even pressure distribution } \\
\text { Does not require interlocking screws or reaming } \\
\text { Minimally invasive } \\
\text { Decreased radiation exposure }\end{array}$ & $\begin{array}{l}\text { Risk of fracture extension } \\
\text { Explosion during cremation }\end{array}$ \\
\hline $\begin{array}{l}\text { Coated Nail } \\
\text { (Antibiotics) }\end{array}$ & $\begin{array}{l}\text { High local concentrations without high systemic doses } \\
\text { Reduce implant-related infections } \\
\text { Prevent formation of biofilm }\end{array}$ & Reaming required \\
\hline $\begin{array}{l}\text { Coated Nail } \\
\text { (Anti-septic) }\end{array}$ & $\begin{array}{l}\text { Wide bactericidal activity } \\
\text { Reduced antibiotic resistance }\end{array}$ & Silver toxicity \\
\hline $\begin{array}{l}\text { Coated Nail } \\
\text { (growth- } \\
\text { stimulating) }\end{array}$ & $\begin{array}{l}\text { Osteoinductive effects } \\
\text { Angiogenic effects }\end{array}$ & Risk of ectopic growth \\
\hline $\begin{array}{l}\text { Carbon Fiber } \\
\text { Nail }\end{array}$ & $\begin{array}{l}\text { Even load distribution } \\
\text { Customizable to suit the bone structure } \\
\text { High fatigue strength and low implant failure } \\
\text { High union rates } \\
\text { Radiolucent - improved visualization of bone structures } \\
\text { post-implantation } \\
\text { Radiotherapy - lower effective radiation dose }\end{array}$ & $\begin{array}{l}\text { Lack of evidence of long-term outcomes and } \\
\text { cost-effectiveness } \\
\text { Difficult nail extraction }\end{array}$ \\
\hline
\end{tabular}

revisions since its invention in the $16^{\text {th }}$ century. The advancement of technology and knowledge has allowed numerous novel nails to be created, aiming to address the limitations of current techniques. However, more work is required in this field to establish the safety and long-term efficacy of the novel IMNs.

The main unresolved challenges are providing rotational stability without the need for increased radiation exposure or operative time; improving the rates of a union while preventing increased infection rates, particularly in high energy trauma or patients with multiple comorbidities; and damaging structures inserting a rigid straight IMN.

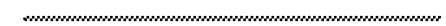

results were discussed within the research group and consensus obtained describing novel IMNs.

\section{DISCLOSURES}

The authors declare no conflicts of interest.

\section{FURTHER INFORMATION}

Contents of the review has been presented in the Australian Orthopedic Association SA/NT Branch 2020 Virtual Annual Scientific Meeting.

Submitted: April 28, 2021 EST, Accepted: July 02, 2021 EST

\section{AUTHORS' CONTRIBUTIONS}

Five independent researchers reviewed the paper, and the 


\section{REFERENCES}

1. Farill J. Orthopaedics in Mexico. J Bone Joint Surg. 1952;34(3):506-512.

2. Meccariello L, Bisaccia M, Caraffa A, et al. From the down to modern era: the history of the nailing. Canadian Open Orthopaedics and Traumatology Journal. 2016;3:10-17.

3. Bong MR, Koval KJ, Egol KA. The history of intramedullary nailing. Bull Hosp Jt Dis. 2006;64(3-4):94.

4. Gluck T. Autoplastik, transplantation, implantation vom fremdkörpern. In: Gesellschaft Vorstand dervortrag, ed. Verhandlungen der Berliner medicinischen Gesellschaft aus dem Gesellschaftsjahre. Schumacher; 1890:79-98.

5. Watson-Jones R, Adams JC, Bonnin JG, et al. Medullary nailing of fractures after fifty years. $J$ Bone Joint Surg. 1950;32-B(4):694-729. doi:10.1302/0301-6 20x.32b4.694

6. Seligson D. History of intramedullary nailing. In: Rommens P, Hessmann M, eds. Intramedullary Nailing. Springer; 2015:3-12.

7. Knothe U, Knothe Tate ML, Perren SM. 300 years of intramedullary fixation - from Aztec practice to standard treatment modality. Eur J Trauma. 2000;26(5):217-225. doi:10.1007/PL00002445

8. Galakatos GR. Direct anterior total hip arthroplasty. Mo Med. 2018;115(6):537-541.

9. Groves EWH. On the application of the principle of extension to comminuted fractures of the long bone, with special reference to gunshot injuries. Brit J Surg. 1914;2(7):429-443. doi:10.1002/bjs.1800020713

10. Hoeppner DW, Chandrasekaran V. Fretting in orthopaedic implants: a review. Wear. 1994;173(1):189-197. doi:10.1016/0043-1648(94)9027 $\underline{2-0}$

11. Browner B, Jupiter J, Krettek C, Anderson P. Skeletal Trauma: Basic Science, Management, and Reconstruction. 5th ed. Saunders Elsevier; 2014.

12. Smith-Petersen MN, Cave EF, Vangorder GW. Intracapsular fractures of the neck of the femur: treatment by internal fixation. AArch Surg. 1931;23(5):715-759. doi:10.1001/archsurg.1931.01160 110002001
13. Born CT, Pidgeon T, Taglang G. 75 years of contemporary intramedullary nailing. J Orthop Trauma. 2014;28:S1-S2. doi:10.1097/bot.0000000000 $\underline{000163}$

14. Küntscher G. Die Marknalung von Knochenbruchen. Langenbecks Arch Klin Chir. 1940;200:443-455.

15. DeCoster T. A brief history of medullary nailing, New Mexico perspective. University of New Mexico Orthopaedics Research Journal. 2012;1:46-54.

16. Rosa N, Marta M, Vaz M, et al. Intramedullary nailing biomechanics: evolution and challenges. Proc Inst Mech Eng [H]. 2019;233(3):295-308. doi:10.1177/0 $\underline{954411919827044}$

17. Modny MT, Bambara J. The perforated cruciate intramedullary nail: preliminary report of its use in geriatric patients. J Am Geriatr Soc.

1953;1(8):579-588. doi:10.1111/j.1532-5415.1953.tb0 $\underline{3935 . x}$

18. Siegel HJ, Sessions W, Casillas MA Jr. Stabilization of pathologic long bone fractures with the fixion expandable nail. Orthopedics. 2008;31(2):143.

19. Levy MM, Greenberg I. Inventors; Expanding Orthopedics, Inc., Boston, MA (US) assignee. Expanding Orthopedic Device. United States patent US 6,554,833 B2. Published online 2003.

20. Fortis AP, Dimas A, Lamprakis AA. Expandable nailing system for tibial shaft fractures. Injury. 2008;39(8):940-946. doi:10.1016/j.injury.2008.01.022

21. Lepore L, Lepore S, Maffulli N. Intramedullary nailing of the femur with an inflatable self-locking nail: comparison with locked nailing. J Orthop Sci. 2003;8(6):796-801. doi:10.1007/s00776-003-0709-8

22. Blomquist J, Lundberg OJ, Gjerdet NR, Mølster A. Are inflatable nails an alternative to interlocked nails in tibial fractures? Clin Orthop Related Res. 2008;466(5):1225-1231. doi:10.1007/s11999-008-016 $\underline{9-8}$

23. Ozturk H, Unsaldi T, Oztemur Z, Bulut O, Korkmaz M, Demirel H. Extreme complications of fixation nail in treatment of long bone fractures. Arch Orthop Trauma Surg. 2008;128(3):301-306. doi:10.1007/s0040 2-007-0458-9 
24. Sipahioglu S, Zehir S, Sarikaya B, Isikan UE. Comparision of the expandable nail with locked nail in the treatment of closed diaphyseal fractures of femur. Niger J Clinical Prac. 2017;20(7):792-798. doi:1 0.4103/1119-3077.212452

25. Phillips AW, Patel AD, Donell ST. Explosion of fixion humeral nail during cremation: novel “"complication" with a novel implant. Injury Extra. 2006;37:357-358. doi:10.1016/i.injury.2006.03.012

26. Basaran T, Calbiyik M, Basaran PÖ, Hassa E, Ipek D. Blade expandable intramedullary nails for fixation of tibial shaft fractures. Acta Orthop Belg. 2019;85(4):472-476.

27. Plenert T, Garlichs G, Nolte I, et al. Biomechanical comparison of a new expandable intramedullary nail and conventional intramedullary nails for femoral osteosynthesis in dogs. PLOS ONE. 2020;15(5):e0231823. doi:10.1371/journal.pone.0231 $\underline{823}$

28. Galvain T, Chitnis A, Paparouni K, Tong C, Holy $\mathrm{CE}$, Giannoudis PV. The economic burden of infections following intramedullary nailing for a tibial shaft fracture in England. BMJ Open.

2020;10(8):e035404. doi:10.1136/bmiopen-2019-0354 $\underline{04}$

29. McConoughey SJ, Howlin R, Granger JF, et al. Biofilms in periprosthetic orthopedic infections. Future Microbiol. 2014;9(8):987-1007. doi:10.2217/fm b.14.64

30. Fuchs T, Schmidmaier G, Raschke MJ, Stange R. Bioactive-coated implants in trauma surgery. Eur J Trauma Emerg S. 2008;34(1):60-68. doi:10.1007/s0006 8-006-6110-5

31. ter Boo GA, Grijpma DW, Moriarty TF, Richards RG, Eglin D. Antimicrobial delivery systems for local infection prophylaxis in orthopedic- and trauma surgery. Biomaterials. 2015;52:113-125. doi:10.1016/ j.biomaterials.2015.02.020

32. Nizegorodcew T, Palmieri G, Marzetti E. Antibiotic-coated nails in orthopedic and trauma surgery: state of the art. Int J Immunopath Ph. 2011;24(1 suppl2):125-128. doi:10.1177/0394632011 0241s223

33. van de Belt H, Neut D, Uges DRA, et al. Surface roughness, porosity and wettability of gentamicinloaded bone cements and their antibiotic release. Biomaterials. 2000;21(19):1981-1987. doi:10.1016/s01 42-9612(00)00082-x
34. Diefenbeck M, Mückley T, Hofmann GO. Prophylaxis and treatment of implant-related infections by local application of antibiotics. Injury. 2006;37:S95-104. doi:10.1016/j.injury.2006.04.015

35. Metsemakers WJ, Reul M, Nijs S. The use of gentamicin-coated nails in complex open tibia fracture and revision cases: a retrospective analysis of a single centre case series and review of the literature. Injury. 2015;46(12):2433-2437. doi:10.101 6/j.injury.2015.09.028

36. Barger J, Fragomen AT, Rozbruch SR. Antibioticcoated interlocking intramedullary nail for the treatment of long-bone osteomyelitis. J Bone Joint Surg. 2017;5(7):e5. doi:10.2106/JBJS.RVW.16.00095

37. Ramot Y, Nedvetzki S, Rosenfeld S, Rousselle SD, Nyska A, Emanuel N. D-PLEX100 in an abdominal surgery incision model in miniature swine: safety study. Toxicol Pathol. 2020;48(5):677-685. doi:10.117 7/0192623320928902

38. Klemm K, Henry SL, Seligson D. The treatment of infection after interlocking nailing. Techniques in Orthopaedics. 1988;3(3):54-61. doi:10.1097/0001361 $\underline{1-198810000-00010}$

39. Reilly RM, Robertson T, O’Toole RV, Manson TT. Are antibiotic nails effective in the treatment of infected tibial fractures? Injury. 2016;47(12):2809-2815. doi:10.1016/i.injury.2016.1 $\underline{0.010}$

40. Kim JW, Cuellar DO, Hao J, Seligson D, Mauffrey C. Custom-made antibiotic cement nails: a comparative study of different fabrication techniques. Injury. 2014;45(8):1179-1184. doi:10.1016/j.injury.201 $\underline{4.03 .006}$

41. Noh JH, Koh SJ, Lee KH. Treatment of proximal femur osteomyelitis occurred after proximal femoral nail antirotation fixation, with antibiotic cementcoated tibia intramedullary nail: a case report. Hip \& Pelvis. 2018;30(1):45-52. doi:10.5371/hp.2018.30.1.45

42. Mijnendonckx K, Leys N, Mahillon J, Silver S, Van Houdt R. Antimicrobial silver: uses, toxicity and potential for resistance. Biometals. 2013;26(4):609-621. doi:10.1007/s10534-013-9645-Z

43. Davies J, Wright GD. Bacterial resistance to aminoglycoside antibiotics. Trends Microbiol. 1997;5(6):234-240. doi:10.1016/S0966-842X(97)0103 $\underline{3-0}$

44. Hardes J, von Eiff C, Streitbuerger A, et al. Reduction of periprosthetic infection with silvercoated megaprostheses in patients with bone sarcoma. J Surg Oncol. 2010;101(5):389-395. doi:10.10 $\underline{02 / \text { iso. } 21498}$ 
45. Gallo J, Holinka M, Moucha CS. Antibacterial surface treatment for orthopaedic implants. Int J Mol Sci. 2014;15(8):13849-13880. doi:10.3390/ijms150813 $\underline{849}$

46. Hodgkinson V, Petris MJ. Copper homeostasis at the host-pathogen interface. J Biol Chem. 2012;287(17):13549-13555. doi:10.1074/jbc.R111.316 406

47. Tsuchiya $H$, Shirai $T$, Nishida $H$, et al. Innovative antimicrobial coating of titanium implants with iodine. J Orthop Sci. 2012;17(5):595-604. doi:10.1007/ $\underline{\text { s00776-012-0247-3 }}$

48. Savvidou OD, Kaspiris A, Trikoupis I, et al. Efficacy of antimicrobial coated orthopaedic implants on the prevention of periprosthetic infections: a systematic review and meta-analysis. J Bone Joint Infect. 2020;5(4):212-222. doi:10.7150/ibji.44839

49. Schmidmaier G, Wildemann B, Stemberger A, Haas NP, Raschke M. Biodegradable poly(D,L-lactide) coating of implants for continuous release of growth factors. J Biomed Mater Res. 2002;58(4):449-455. doi:1 $\underline{0.1002 / \mathrm{jbm} .1040}$

50. Raschke M, Wildemann B, Inden $\mathrm{P}$, et al. Insulinlike growth factor-1 and transforming growth factor$\beta 1$ accelerates osteotomy healing using polylactidecoated implants as a delivery system: a biomechanical and histological study in minipigs. Bone. 2002;30(1):144-151. doi:10.1016/S8756-3282(01)0064 0-8

51. Begam H, Nandi SK, Kundu B, Chanda A. Strategies for delivering bone morphogenetic protein for bone healing. Mater Sci Eng C Mater Biol Appl. 2017;70(Pt 1):856-869. doi:10.1016/j.msec.2016.09.07 $\underline{4}$

52. Brohede U, Forsgren J, Roos S, Mihranyan A, Engqvist H, Strømme M. Multifunctional implant coatings providing possibilities for fast antibiotics loading with subsequent slow release. J Mater Sci Mater Med. 2009;20(9):1859-1867. doi:10.1007/s1085 6-009-3749-6
53. Borcherding K, Schmidmaier G, Hofmann GO, Wildemann $\mathrm{B}$. The rationale behind implant coatings to promote osteointegration, bone healing or regeneration. Injury. Published online 2020. doi:10.10 16/j.injury.2020.11.050

54. Cheung G, Zalzal P, Bhandari M, Spelt JK, Papini $M$. Finite element analysis of a femoral retrograde intramedullary nail subject to gait loading. Med Eng Phys. 2004;26(2):93-108. doi:10.1016/i.medengphy.20 $\underline{03.10 .006}$

55. Vles GF, Brodermann MH, Roussot MA, Youngman J. Carbon-fiber-reinforced PEEK intramedullary nails defining the niche. Case Reports in Orthopedics. 2019;2019. doi:10.1155/2019/1538158

56. Hak DJ, Mauffrey C, Seligson D, Lindeque B. Use of carbon-fiber-reinforced composite implants in orthopedic surgery. Orthopedics.

2014;37(12):825-830. doi:10.3928/01477447-2014112 4-05

57. Steinberg EL, Rath E, Shlaifer A, Chechik O, Maman E, Salai M. Carbon fiber reinforced PEEK Optima--a composite material biomechanical properties and wear/debris characteristics of CF-PEEK composites for orthopedic trauma implants. J Mech Behav Biomed. 2013;17:221-228. doi:10.1016/i.jmbb $\underline{\text { m.2012.09.013 }}$

58. Takashima K, Nakahara I, Uemura K, et al. Clinical outcomes of proximal femoral fractures treated with a novel carbon fiber-reinforced polyetheretherketone intramedullary nail. Injury. 2020;51(3):678-682. doi:1 $\underline{0.1016 / j . i n j u r y .2020 .01 .007}$

59. Zoccali C, Soriani A, Rossi B, Salducca N, Biagini R. The Carbofiô" "Piccolo Proximal femur nail”: A new perspective for treating proximal femur lesion. A technique report. J Orthop. 2016;13:343-346.

60. Mitchell P, Lee AK, Collinge CA, Ziran B, Hartley $\mathrm{K}$, Jahangir A. Early comparative outcomes of carbon fiber-reinforced polymer plate in the fixation of distal femur fractures. J Orthop Trauma. 2018;32:386-390. 며 oi:10.1097/BOT.0000000000001223 